\title{
AGRUPAMENTOS DE AMOSTRAS CIRCULARES EM FUNÇÃO DAS UNIDADES DE SOLO
}

\section{SÉRGIO CAMPOS ${ }^{1}$; TERESA CRISITNA TARLÉ PISSARRA ${ }^{2}$; DANIELA POLIZELI TRAFICANTE ${ }^{1}$; ELEN FITTIPALDI BRASÍLIO CARREGA ${ }^{1}$; MARCELO ZANATA ${ }^{2}$ E FABIANA CAMARGO DOS REIS ${ }^{2}$}

\footnotetext{
${ }^{1}$ Departamento de Engenharia Rural, Faculdade de Ciências Agronômicas, Universidade Estadual Paulista, Botucatu, SP, seca@fca.unesp.br

2 Departamento de Engenharia Rural, Faculdade de Ciências Agrárias e Veterinárias, Universidade Estadual Paulista, Jaboticabal, SP, teresap@fcav.unesp.br
}

\section{RESUMO}

Este trabalho visou analisar os atributos do relevo através das variáveis: altitude máxima (HM); altitude média (Hmd); altitude mínima (Hm); a amplitude altimétrica $(\mathrm{H})$; comprimento médio de vertente $(\mathrm{CVm})$; comprimento mínimo de deflúvio $(\mathrm{Cd})$ e declividade média da amostra circular (I) da Bacia Hidrográfica do Rio Capivara - Botucatu (SP) obtidos em quatro amostras circulares por unidade de solo (Neossolo Quartzarênico Órtico Argissólico e Latossólico - RQ, Latossolos Vermelhos-Amarelo - LVA e Neossolos Litólicos - RL), através da análise multivariada e utilizando-se de fotografias aéreas coloridas do ano 2000; da Carta do Brasil e da Carta de Solos do Município de Botucatu - SP. A distinção dos solos foi realizada através do teste "t" para verificação dos contrastes ortogonais entre as médias dos três solos e da análise de agrupamentos e de componentes principais. Os resultados permitiram concluir que as variáveis do relevo submetidas à análise de agrupamento discriminaram $75 \%$ das amostras circulares representativas do solo LVA e $100 \%$ dos solos RL e RQ. Os parâmetros do relevo mais eficientes na diferenciação dos solos por ordem de importância foram: HM, Hm, Hmd e H.

Palavras-chave: análise multivariada, bacia hidrográfica, relevo.

\section{CAMPOS, S., PISSARRA, T.C.T., TRAFICANTE, D.P., CARREGA, E.F.B., PARIZOTO, N.M.S.F., ZANATA, M., REIS, F.C. GROUPINGS OF CIRCULAR SAMPLES AS A FUNCTION OF SOIL UNITS}

\section{ABSTRACT}

The objective of the study was to analyze the features of the relief through the variables: maximum altitude $(\mathrm{HM})$; mean altitude $(\mathrm{Hmd})$; minimum altitude $(\mathrm{Hm})$; altitude range $(\mathrm{H})$; average slope length $(\mathrm{CVm})$; minimum length of run-off $(\mathrm{Cd})$ and average steepness of circular samples (I) of the Capivara River Watershed - Botucatu (SP). A total of 4 circular samples were obtained per unit of soil (Quartzipsamment alfisol oxisol - RQ, Udox - LVA and Udorthent - RL). Multivariable analysis and aerial color photographs of 2000, Brazilian Chart and Soil Chart of Botucatu city- SP were used for data analyses. Soil differentiation was performed using the Student-t Test for analyzes of orthogonal contrasts among means of the three soils and analysis of groupings and major components. The grouping analysis of the variables of relief differentiated $75 \%$ of LVA and $100 \%$ of RL and 
RQ soil circular samples. The most efficient parameters of relief for differentiation of soils according to their order of importance were as follows: $\mathrm{HM}, \mathrm{Hm}, \mathrm{Hmd}$ and $\mathrm{H}$.

Keywords: multivariable analysis, watershed, relief.

\section{INTRODUÇÃO}

O conhecimento dos solos ocorrentes numa área é muito importante no planejamento do meio físico desta, principalmente quando queremos implantar práticas conservacionistas correlatas com as características das classes de solo e avaliação de suas potencialidades.

Atualmente, os estudos fotointerpretativos de redes de drenagem em solos, têm sido constatados por diversos pesquisadores, que solos iguais possuem padrões semelhantes.

A medição de dados experimentais é fundamental para a evolução da ciência; assim o Sensoriamento Remoto vem se constituindo numa solução para levantar o potencial e as condições de cada espécie de recurso presente, pois abrange desde as fotografias aéreas, até as imagens de radar e de satélites (CRUZ, 1981).

A análise de amostras circulares por meio do relevo, permite inferir sobre a natureza e distribuição dos solos. O estudo hipsométrico das amostras circulares, conjuntamente com as características da rede de drenagem, constitui um meio consistente na comparação entre o estágio de evolução e das unidades de solos.

A análise multivariada é uma técnica estatística que vem sendo utilizada com sucesso por muitos pesquisadores em variáveis da rede de drenagem e do relevo, como Kofller (1982), Barros (1988), Cardoso (1988), Campos e Barros (1994), etc.

A análise dos componentes principais permite a verificação em ordem de importância de cada variável original na discriminação de bacias hidrográficas e amostras circulares na constituição dos agrupamentos (CURI, 1983).

O teste "t" para determinar os contrastes ortogonais entre as médias das variáveis da rede de drenagem e de relevo vem sendo aplicado na discriminação de solos por muitos pesquisadores.

Assim, este trabalho objetivou com auxílio de técnicas fotointerpretativas e da análise multivariada de amostras circulares, avaliar as características do relevo na discriminação de três unidades de solo (LVA, RL e RQ) ocorrentes da Bacia Hidrográfica do Rio Capivara Botucatu (SP).

\section{MATERIAL E MÉTODOS}

Este trabalho foi desenvolvido na Bacia Hidrográfica do Rio Capivara, com uma área de 37.840,03 hectares, a qual está localizada no Município de Botucatu (SP), entre os paralelos $22^{\circ} 39^{\prime} 36^{\prime \prime}$ a $22^{\circ} 57^{\prime} 39^{\prime \prime}$ de latitude S e os meridianos $48^{\circ} 17^{\prime} 34^{\prime \prime}$ a $48^{\circ} 29^{\prime} 36^{\prime \prime}$ de longitude $\mathrm{W}$ Gr.

Os solos (Figura 1) ocorrentes na área foram classificados como: Neossolo Quartzarênico Órtico Argissólico e Latossólico (RQ), Latossolos Vermelhos-Amarelo (LVA) e Neossolos Litólicos (RL), segundo Campos (1995). 


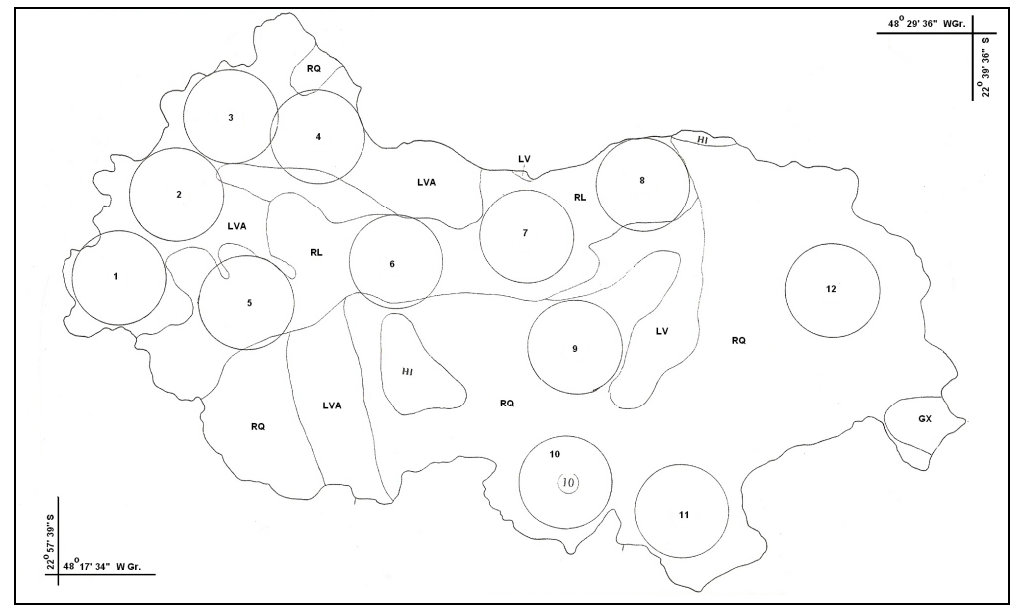

Figura 1. Unidades de solos da bacia do Rio Capivara, Botucatu, SP (CAMPOS, 1995) e a localização das 12 amostras circulares estudadas.

As unidades Neossolo Quartzarênico Órtico Argissólico e Latossólico (RQ), conforme Campos (1995), são solos profundos, de textura muito leve, acentuadamente drenados, de cor geralmente vermelho amarelado, com seqüência de horizontes A, B e C, originados a partir de arenitos, de fertilidade baixa, ácidos e muito susceptíveis à erosão.

O conteúdo de argila é baixo, sendo menor de $15 \%$, variando de 7,8 a $15 \%$ nos horizontes A e B, enquanto que o conteúdo de silte no horizonte B varia de 0,2 a 2,3\%.

$\mathrm{O}$ relevo predominante é o suavemente ondulado a ondulado. Quando suavemente ondulado, as colinas apresentam declives suaves e formam vales em berço abertos e, quando ondulados, as colinas ou morros são mais declivosos e os vales em V mais fechados.

A altitude varia de 420 a 740 metros, sendo nas partes altas de 600 a 740 metros e nas baixas de 420 a 600 metros.

A vegetação predominante é a do tipo cerrado e o material original é arenito da Formação Pirambóia.

O Neossolos Litólicos (RL), conforme Campos (1995), são solos poucos desenvolvidos com espessura em torno de $35 \mathrm{~cm}$, constituídos pelo horizonte A e a camada D. Granulometricamente, apresentam o conteúdo de argila em torno de $46,7 \%$, sendo a fração silte muito baixa, em torno de $2,1 \%$.

Estes solos ocupam os topos das elevações, distribuídos em pequenas manchas esparsas, sendo o relevo forte ondulado de topos arredondados, vertentes convexas, vales em $\mathrm{V}$ com declive em torno de $40 \%$ e a altitude em torno de 700 metros.

O clima predominante é o do tipo Cfa e o material original é o basalto (Formação Serra Geral), metáfiro e provavelmente diabásico (eruptivas básicas).

A vegetação nativa predominante nestes solos é a floresta latifoliada tropical.

As áreas mapeadas por Campos (1993) como pertencentes à unidade Latossolos Vermelhos-Amarelo (LVA), caracterizam-se por serem solos profundos, de textura leve, bem drenados, de coloração vermelho amarelado, formados a partir de arenito de Botucatu, ácidos, de baixa fertilidade, de pequenas variações nas características, fazendo com que os vários subhorizontes se apresentem pouco individualizados, com transição variando de gradual a difusa.

A composição granulométrica deste solo apresenta o conteúdo de argila entre 15 a $30 \%$, nos horizontes A e B, sendo geralmente o teor de argila no horizonte C menor que no B.

Estes solos localizam-se na região do Alto Planalto Central, onde formam manchas contínuas entrecortadas por solos de outras unidades. Geralmente encontram-se nas 
superfícies dos espigões, que podem ser estreitas ou muito largas, apresentando uma topografia suavemente ondulada com pendentes de centenas de metros, ou completamente plana e, muito raramente, ondulada e mesmo assim de pendentes alongadas.

A altitude varia de 500 a 1.000 metros, estando a sua maior parte entre 600 a 900 metros.

A cobertura vegetal é variável, apresentando nas partes altas campo limpo, campo cerrado e cerrado, nas partes baixas é mais fina e de arbustos tortuosos, mas predominando campo cerrado e, nas transições, apresenta capoeira e cerradão quando a unidade vizinha é o Nitossolo Vermelho (NV), contudo os arbustos do cerrado são mais eretos e vigorosos.

O clima predominante para esta unidade de solo é o Cfa, com índice pluviométrico variando de 1.100 a $1.700 \mathrm{~mm}$.

O material de origem desses solos é constituído por arenito da Formação Botucatu e da Formação Furnas, possivelmente sedimentos do terciário.

Foram utilizadas as fotografias aéreas verticais coloridas do ano 2.000, em escala nominal aproximada de 1:30.000, para elaboração do mapa da rede de drenagem da Bacia Hidrográfica do Rio Capivara - Botucatu -SP (Figura 2) e da Carta de Solos do Município de Botucatu -SP (Figura 1), na escala 1:50.000, para identificação dos limites das unidades de solo e a localização das 12 amostras circulares de $10 \mathrm{~km}^{2}$, objeto de estudo neste trabalho, sendo os pontos de apoio cartográfico obtidos na Carta do Brasil, escala 1:50000, editada pelo IBGE (1969).

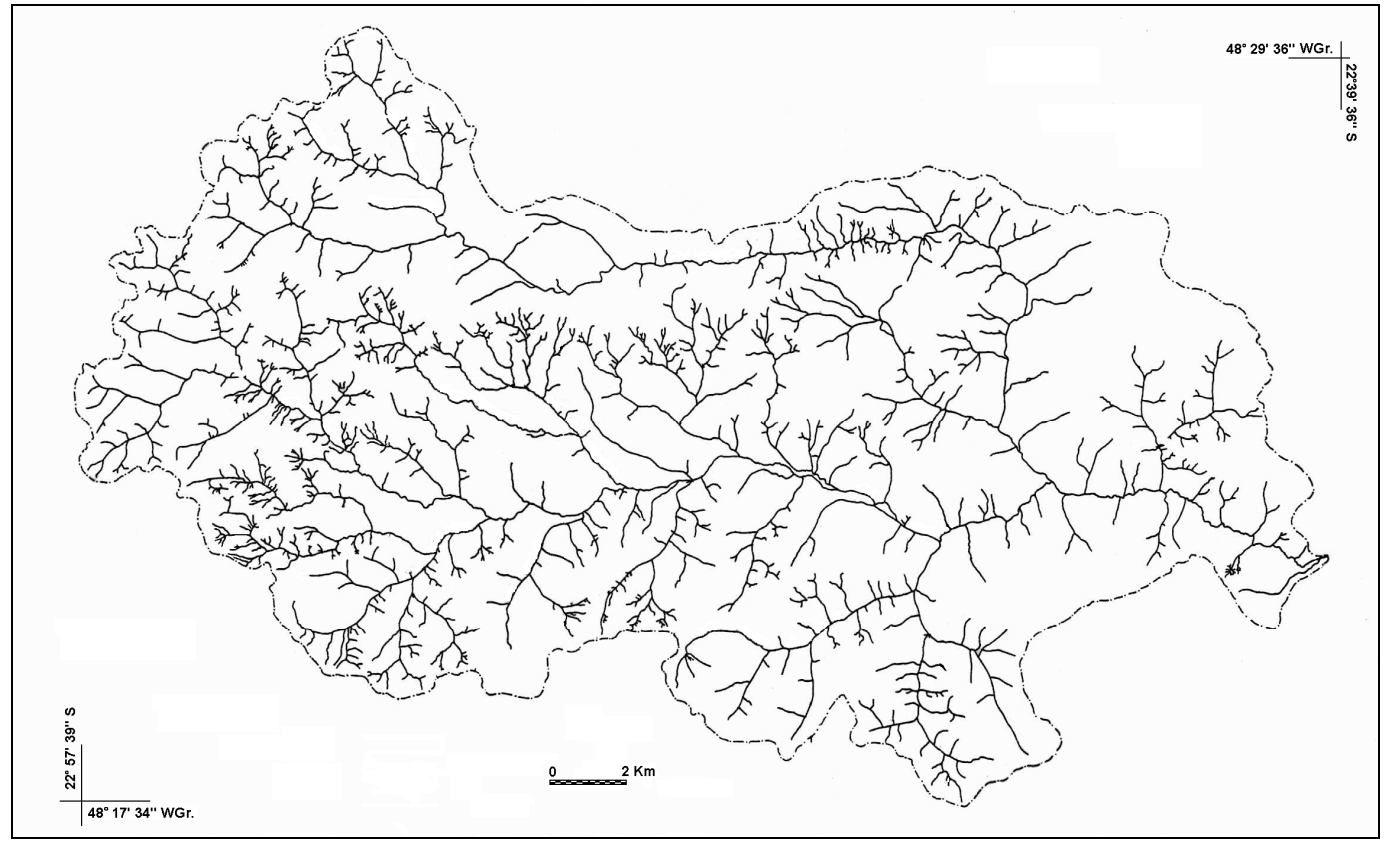

Figura 2. Rede de drenagem da bacia do Rio Capivara, Botucatu, SP.

As áreas foram determinadas com auxílio do Software SPLAN -Sistema de Planimetria Digitalizada (Silva et al., 1993) e as distâncias retas foram efetuadas com auxílio do compasso de ponta seca e da escala triangular, sendo as distâncias curvas determinadas com o curvímetro, da marca DERBY.

Após o decalque da rede de drenagem das fotos, utilizando-se dos estereoscópicos de espelho marca WILD, modelo ST4, efetuou-se o enriquecimento da rede de drenagem constante do mapa básico, transferindo-se os detalhes obtidos de cada foto para a carta base, com o auxílio do Aerosketchmaster, marca Carl Zeiss, JENA. 
A partir das Cartas do Brasil, em escala 1:50.000, identificaram-se as 12 amostras circulares (Figura 1), através de seus divisores de água, decalcando em filme de poliéster Terkron D - 50u, as curvas de nível eqüidistantes de 20 em 20 metros, correspondentes às amostras.

Os atributos do relevo foram analisados através das variáveis: altitude máxima (HM); altitude média (Hmd); amplitude altimétrica $(\mathrm{H})$; comprimento médio de vertente $(\mathrm{CVm})$; comprimento mínimo de deflúvio (Cd); Declividade média da amostra circular (I) .

- Altitude máxima (HM) - maior altitude ocorrente na amostra, conforme Moreira e Rodrigues (2010);

- Altitude mínima (Hm) - menor altitude ocorrente na amostra, conforme Moreira e Rodrigues (2010);

- Altitude média (Hmd) - média aritmética entre os valores de cota mais alta (HM) e cota mais baixa (Hm), conforme Moreira e Rodrigues (2010);

- Amplitude altimétrica (H) - diferença entre a maior e a menor altitude, conforme Moreira e Rodrigues (2010);

- Declividade média da amostra circular (I) - determinada pelo método de Wentworth (1930) e adaptado para amostragem circular e sistema métrico decimal por Koffler (1982), pela fórmula: I\% = E . N/636,6 . 100, onde E é a eqüidistância vertical das curvas de nível em metros, $\mathrm{N}$ é o número médio de curvas de nível interceptadas por quilômetro, por retas dispostas nas direções Norte-Sul, Leste-Oeste, Noroeste-Sudeste e Nordeste-Sudoeste e por perpendiculares a estas direções passando pelos pontos $\mathrm{D} / 4$, sendo $\mathrm{D}$ o diâmetro da amostra e 636,6 uma constante gerada pela transformação da fórmula original para o sistema métrico decimal (Figura 3).

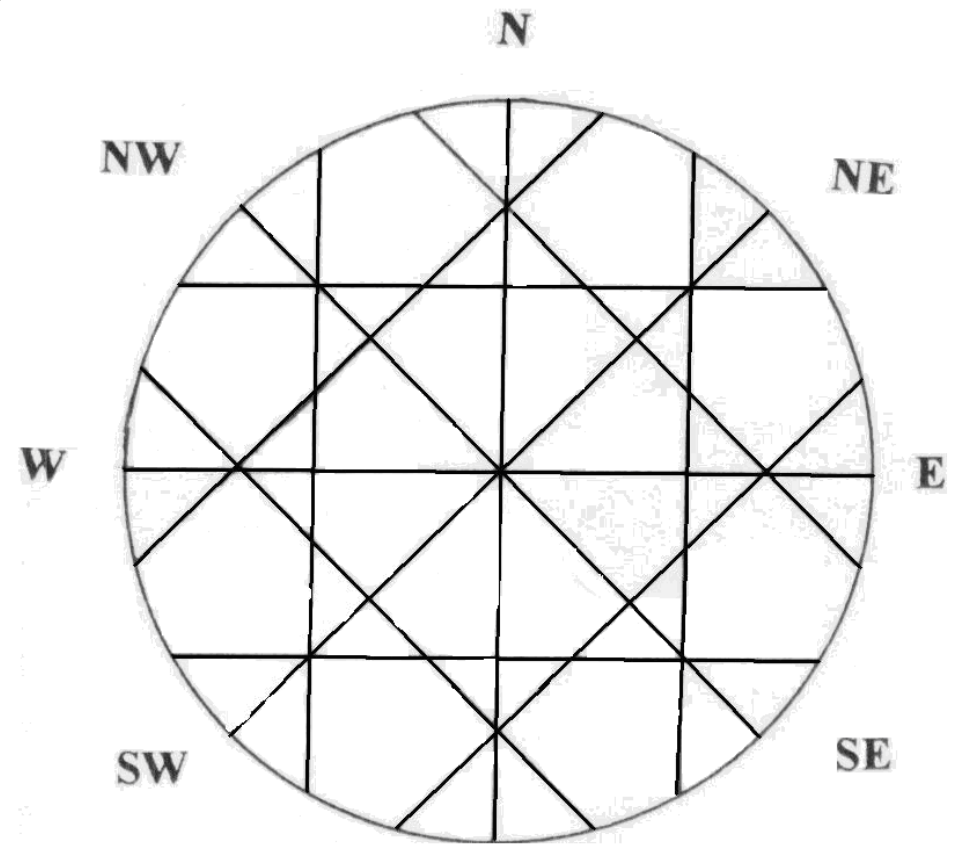

$\mathrm{S}$

Figura 3. Modelo de Wentworth (1930) adaptado por Koffler (1982) para determinação de declividade média de amostras circulares.

- Comprimento médio de vertente $(\mathrm{CVm})$ : obtido conforme procedimento descrito por Angulo Filho (1986), Lima (1987) e Silva (1988). Segundo esses autores o procedimento consiste em medir com auxílio de uma escala graduada a distância entre os pontos de cotas mais elevadas e o canal de drenagem, procurando medir somente os comprimentos das linhas 
normais aos canais de drenagem (Figura 4) e por cálculo obtém-se o comprimento médio da vertente, em metros, de todas as leituras possíveis obtidas em cada amostra circular (ou bacia hidrográfica).

Para padronizar a obtenção desse parâmetro para todas as amostras utilizadas optou-se por adotar o seguinte procedimento (SILVA, 1988):

Traçar estereoscopicamente os divisores de água da rede de drenagem e transferi-los para as amostras circulares contendo a rede de drenagem e as curvas de nível;

Traçar uma reta acompanhando a direção geral dos canais de drenagem considerados;

Medir com escala triangular, o comprimento das linhas perpendiculares a reta a cada 0,5 $\mathrm{km}$ ao longo desta entre o divisor de águas e o canal de drenagem.

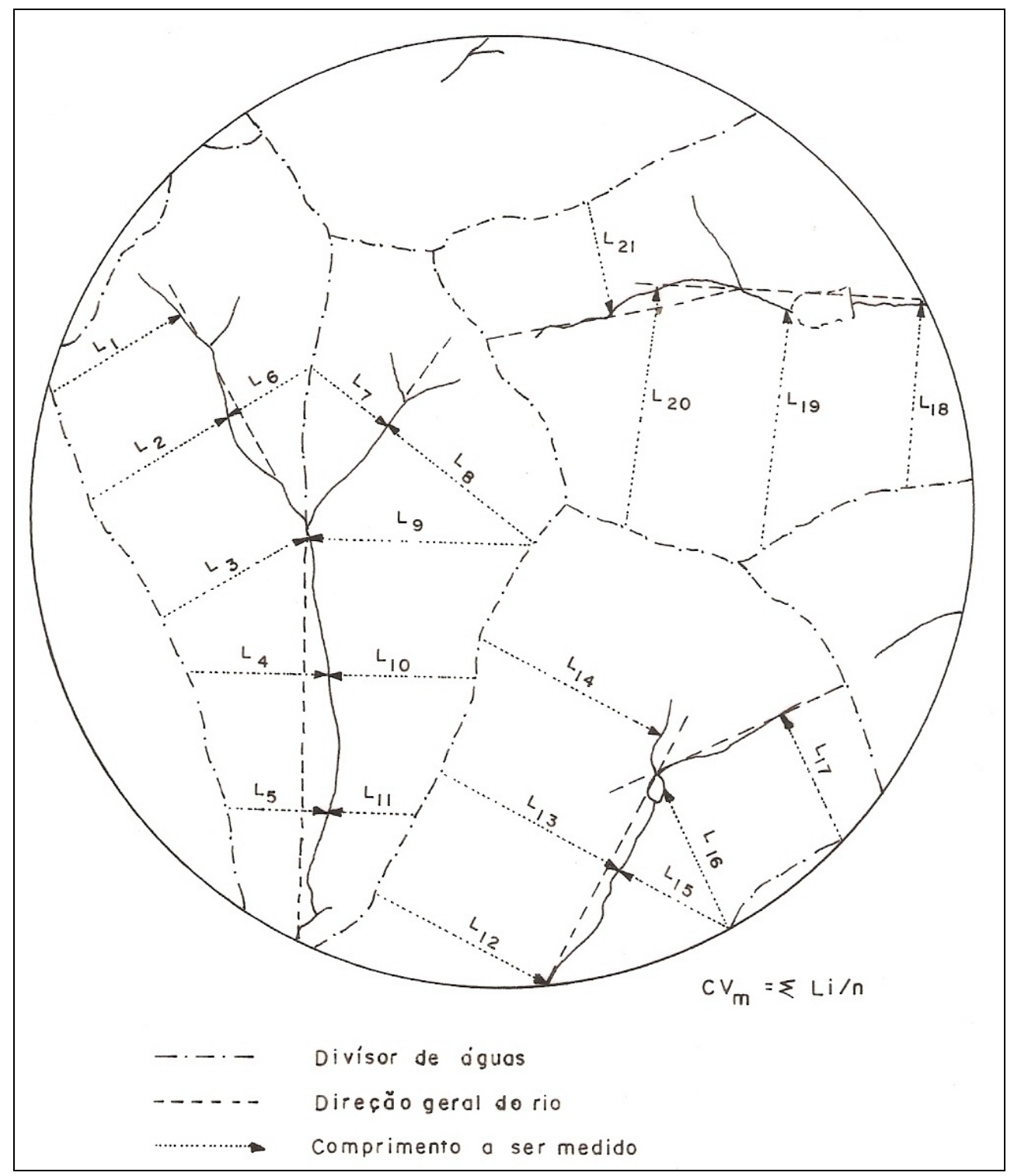

Figura 4. Representação esquemática para obtenção do comprimento médio de vertente (SILVA, 1988).

- Comprimento mínimo de deflúvio (Cd): obtido pela fórmula $\mathrm{Cd}=\Sigma \mathrm{li} / \mathrm{n}$; onde li é a extensão em metros de cada comprimento mínimo de deflúvio e $\mathrm{n}$ é o número de medidas efetuadas em cada amostra circular. Este índice representa a média do comprimento mínimo de escoamento sobre a superfície em cada amostra, necessário para concentrar um volume de 
deflúvio suficiente para iniciar a formação de canais (HORTON, 1945). Para a obtenção deste valor, mediu-se com curvímetro, o prolongamento dos canais de drenagem de primeira ordem de ramificação até o divisor de águas através de observações estereoscópicas procurando-se as linhas sensíveis de conduzir o deflúvio ao canal de drenagem (Figura 5).

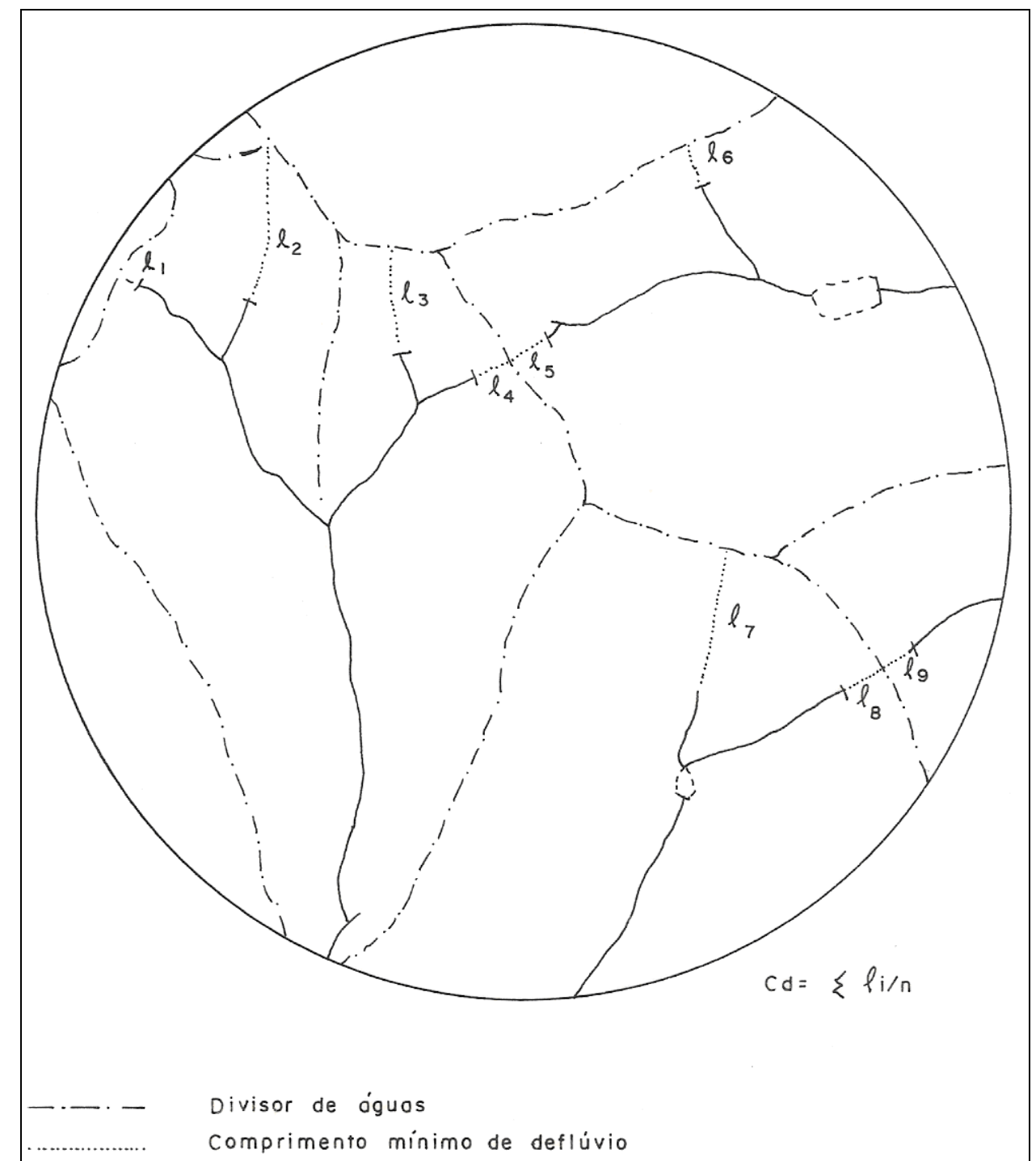

Figura 5. Representação esquemática da forma de medir o comprimento mínimo de deflúvio (SILVA, 1988).

Foi também utilizada a análise multivariada, utilizando-se como coeficiente de semelhança a Distância Euclideana Média entre os pares de bacias hidrográficas de terceira ordem de ramificação e de amostras circulares de $10 \mathrm{~km}^{2}$ de área (SNEATH e SOKAL, 1973), com o objetivo de encontrar a melhor maneira de descrever os padrões de similaridade mútuas entre bacias e entre amostras circulares.

$O$ teste "t" Student foi aplicado com o objetivo de verificação dos contrastes ortogonais entre as médias dos solos $(\mathrm{C} 1=\mathrm{RPV} / \mathrm{RLV} \times \mathrm{Li}-\mathrm{b}, \mathrm{C} 2=\mathrm{RPV}-\mathrm{RLV} \times \mathrm{LVa}, \mathrm{C} 3=$ RPV-RLV x (Li-b + LVa) e C4 = LVa x Li-b), bem como, analisar as variáveis do relevo que mais contribuíram na discriminação dos solos. 


\section{RESULTADOS E DISCUSSÃO}

A região de estudo está localizada em regiões de terras relativamente altas, pois as altitudes variam desde 934 a 454 m, ou seja, com uma amplitude de ocorrência desses solos de $480 \mathrm{~m}$. Essas afirmações podem ser notadas através do Tabela 1, que apresenta maiores valores médios de altitude máxima (HM), mínima $(\mathrm{Hm})$, média $(\mathrm{Hmd})$ e amplitude altimétrica $(\mathrm{H})$, para a unidade de solo LVA e os menores para o solo RQ.

As amplitudes altimétricas relativas às amostras circulares $2(79 \mathrm{~m})$ e $3(89 \mathrm{~m})$ foram menores nas regiões situadas em relevo menos movimentado, localizadas na unidade Latossolo Vermelho Amarelo, enquanto que na amostra circular 5, a amplitude altimétrica de 327 situa-se em relevo forte ondulado (Neossolos Litólicos - RL).

Tabela 1. Variáveis de relevo observadas para as 12 amostras circulares estudadas, na bacia do Rio Capivara - Botucatu (SP) e do contraste obtido do teste " $t$ " por unidade de solo.

\begin{tabular}{|c|c|c|c|c|c|c|c|c|}
\hline $\mathbf{U S}$ & A C & $\begin{array}{c}\mathbf{H ~ M} \\
(\mathbf{m})\end{array}$ & $\begin{array}{l}\mathbf{H m} \\
(\mathbf{m})\end{array}$ & $\begin{array}{c}\mathbf{H ~ m ~ d ~} \\
(\mathbf{m})\end{array}$ & $\begin{array}{c}\mathbf{H} \\
(\mathbf{m})\end{array}$ & $\begin{array}{c}I \\
(\%)\end{array}$ & $\begin{array}{c}\mathbf{C} \text { V V m } \\
\text { (m) }\end{array}$ & $\begin{array}{l}\text { C d } \\
(\mathbf{m})\end{array}$ \\
\hline \multirow{5}{*}{ LVA } & 1 & 930,00 & 805,00 & 867,50 & 125,00 & 7,58 & 335,53 & 204,55 \\
\hline & 2 & 906,00 & 827,00 & 866,50 & 79,00 & 8,58 & 295,19 & 311,54 \\
\hline & 3 & 934,00 & 828,00 & 881,00 & 106,00 & 7,65 & 511,11 & 304,35 \\
\hline & 4 & 885,00 & 796,00 & 840,50 & 89,00 & 8,49 & 825,00 & 371,43 \\
\hline & Média & 913,75 & 814,00 & 863,88 & 99,75 & 8,08 & 491,71 & 297,97 \\
\hline \multirow{5}{*}{ RL } & 5 & 882,00 & 555,00 & 718,50 & 327,00 & 8,42 & 400,83 & 265,22 \\
\hline & 6 & 745,00 & 521,00 & 633,00 & 224,00 & 10,75 & 432,00 & 155,26 \\
\hline & 7 & 785,00 & 512,00 & 648,50 & 273,00 & 8,69 & 386,54 & 244,83 \\
\hline & 8 & 745,00 & 498,00 & 621,50 & 247,00 & 8,26 & 514,66 & 267,86 \\
\hline & Média & 789,25 & 521,50 & 655,38 & 267,75 & 9,03 & 433,51 & 233,29 \\
\hline \multirow{5}{*}{ RQ } & 9 & 592,00 & 487,00 & 539,50 & 105,00 & 7,03 & 378,57 & 269,23 \\
\hline & 10 & 625,00 & 488,00 & 556,50 & 137,00 & 9,46 & 533,33 & 400,00 \\
\hline & 11 & 583,00 & 494,00 & 538,50 & 89,00 & 8,33 & 560,71 & 305,56 \\
\hline & 12 & 585,00 & 454,00 & 519,50 & 131,00 & 10,54 & 425,00 & 392,31 \\
\hline & Média & 596,25 & 480,75 & 538,50 & 115,50 & 8,84 & 474,40 & 341,78 \\
\hline \multicolumn{2}{|c|}{ "t" } & $60,44 * *$ & $338,18 * *$ & $135,35^{* *}$ & $35,95^{* *}$ & $0,79 \mathrm{~ns}$ & $0,16 \mathrm{~ns}$ & $3,04 \mathrm{~ns}$ \\
\hline \multicolumn{2}{|c|}{ Gl } & 11 & 11 & 11 & 11 & 11 & 11 & 11 \\
\hline \multicolumn{2}{|c|}{ CV (\%) } & 5,37 & 3,27 & 4,13 & 19,22 & 13,19 & 32,50 & 21,52 \\
\hline \multirow[t]{2}{*}{$\mathbf{C}_{1}$} & $T$ & $43,98 * *$ & $8,50^{*}$ & $34,03 * *$ & $48,40 * *$ & $0,06 \mathrm{~ns}$ & $0,15 \mathrm{~ns}$ & $6,00^{*}$ \\
\hline & gl & 3 & 3 & 3 & 3 & 3 & 3 & 3 \\
\hline \multirow[t]{2}{*}{$\mathrm{C}_{2}$} & $\mathbf{T}$ & $119,03 * *$ & $568,26 * *$ & $263,72 * *$ & $0,52 \mathrm{~ns}$ & $0,90 \mathrm{~ns}$ & $0,03 \mathrm{~ns}$ & $0,98 \mathrm{~ns}$ \\
\hline & gl & 3 & 3 & 3 & 3 & 3 & 3 & 3 \\
\hline \multirow[t]{2}{*}{$\mathrm{C}_{3}$} & $\mathbf{T}$ & $102,57^{* * *}$ & $238,58 * *$ & $162,40^{* * *}$ & $12,97 * *$ & $0,17 \mathrm{~ns}$ & $0,02 \mathrm{~ns}$ & $3,94 \mathrm{~ns}$ \\
\hline & gl & 3 & 3 & 3 & 3 & 3 & 3 & 3 \\
\hline \multirow[t]{2}{*}{$\mathrm{C}_{4}$} & $T$ & $18,30^{* *}$ & $437,78 * *$ & $108,29 * *$ & $58,93 * *$ & $1,40 \mathrm{~ns}$ & $0,29 \mathrm{~ns}$ & $2,13 \mathrm{~ns}$ \\
\hline & gl & 3 & 3 & 3 & 3 & 3 & 3 & 3 \\
\hline
\end{tabular}

Obs: $\mathbf{A C}=$ Amostra circular; $\mathbf{U S}=$ Unidade de solo $\mathbf{H M}=$ Altitude máxima $\mathbf{H m}=$ Altitude mínima; $\mathbf{H m d}=$ Altitude média; $\mathbf{H}=$ Amplitude altimétrica; $\mathbf{I}=$ Declividade média; $\mathbf{C V m}=$ Comprimento médio da vertente e Cd = Comprimento mínimo de deflúvio; $\mathbf{C 1}=$ RPV/RLV x Li-b; C2 = RPV-RLV x LVa; C3 = RPV-RLV x (Li-b + LVa) e C4 = LVa x Li-b).

Os resultados relativos à declividade média (I) para as unidades de solo LVA, RL e RPV-RQ, respectivamente, $8,08 \%$, 9,03\% e 8,84\%, permitem classificar o relevo de 
ocorrência dos solos LVA e RQ como suavemente ondulado e da unidade RL como forte ondulado.

Os comprimentos médios da vertente $(\mathrm{CVm})$ para as unidades de solo LVA, RL e RQ, respectivamente, da ordem de 491,71m, 433,51m e 474,40m, permitem classificar os declives dos três solos como muito longos, segundo Ranzani (1969) e Silva (1988).

O maior valor médio observado para o comprimento mínimo de deflúvio $(341,78 \mathrm{~m})$ para a unidade de solo RQ, leva a considerar que por ser constituído de solos profundos, arenosos e com excessiva drenagem requer uma maior distância para concentrar o deflúvio necessário para iniciar a formação dos canais.

A localização das amostras circulares segundo os dois componentes principais com base nas sete variáveis de relevo estudadas permitiram constatar que todas amostras circulares confirmaram a ocorrência das três unidades de solos na bacia, com exceção da amostra circular 4, a única que se apresentou deslocada em relação ás demais amostras circulares $(1,2$ e 3) localizadas na unidade de solo LVA (Figura 2).

Os dados médios das variáveis do relevo apresentados pelo teste "t" para os contrastes entre as médias $\mathrm{C}_{1}(\mathrm{RQ} \times \mathrm{RL}), \mathrm{C}_{2}$ (RQ x LVA), $\mathrm{C}_{3}$ [RQ x (RL + LVA)] e $\mathrm{C}_{4}$ (LVA x RL) permitiram constatar que $\mathrm{HM}, \mathrm{Hm}, \mathrm{Hmd}$ e $\mathrm{H}$ foram significativas ao nível de $5 \%$ para todos os contrastes, com exceção da amplitude altimétrica $(H)$ para o contraste $C_{2}$ (RQ x RL), enquanto que a declividade média (I), comprimento médio da vertente $(\mathrm{CVm})$ e de deflúvio (Cd) não apresentaram significância para todos os contrastes. Isto indica que as variáveis HM, Hm, Hmd e H foram eficientes na discriminação dos três solos, porém, as variáveis I, $\mathrm{CVm}$ e $\mathrm{Cd}$ não permitiram diferenciar os solos, com exceção da $\mathrm{Cd}$ que permitiu a diferenciação entre os solos RQ e LVA ao nível de 5\% de probabilidade.

Os valores dos componentes principais $\left(\mathrm{Y}_{1}\right.$ e $\left.\mathrm{Y}_{2}\right)$ obtidos para as variáveis do relevo (Tabela 2 e Figura 6) possibilitaram a representação das amostras circulares em um gráfico bidimensional, bem como o agrupamento de acordo com as proximidades de suas localizações.

Tabela 2. Análise dos componentes principais utilizando-se as variáveis do relevo para amostras circulares que contribuíram para a formação dos agrupamentos. Coeficientes dos dois primeiros componentes principais $\left(\mathrm{Y}_{1}\right.$ e $\left.\mathrm{Y}_{2}\right)$, ordem de importância (OI) e porcentagem da variância total e acumulada.

\begin{tabular}{|c|c|c|c|}
\hline Variáveis & $\mathbf{Y}_{\mathbf{1}}$ & $\mathbf{Y}_{\mathbf{2}}$ & OI \\
\hline HM & 0,521 & $-0,180$ & 2 \\
\hline Hm & 0,548 & 0,135 & 1 \\
\hline Hmd & 0,557 & $-0,015$ & 3 \\
\hline H & $-0,142$ & $-0,554$ & 4 \\
\hline I & $-0,298$ & $-0,020$ & 7 \\
\hline CVm & 0,009 & 0,506 & 6 \\
\hline Cd & $-0,098$ & 0,621 & 5 \\
\hline Variância total (\%) & 44,52 & 26,60 & - \\
\hline Variância acumulada (\%) & 44,52 & 71,12 & - \\
\hline
\end{tabular}




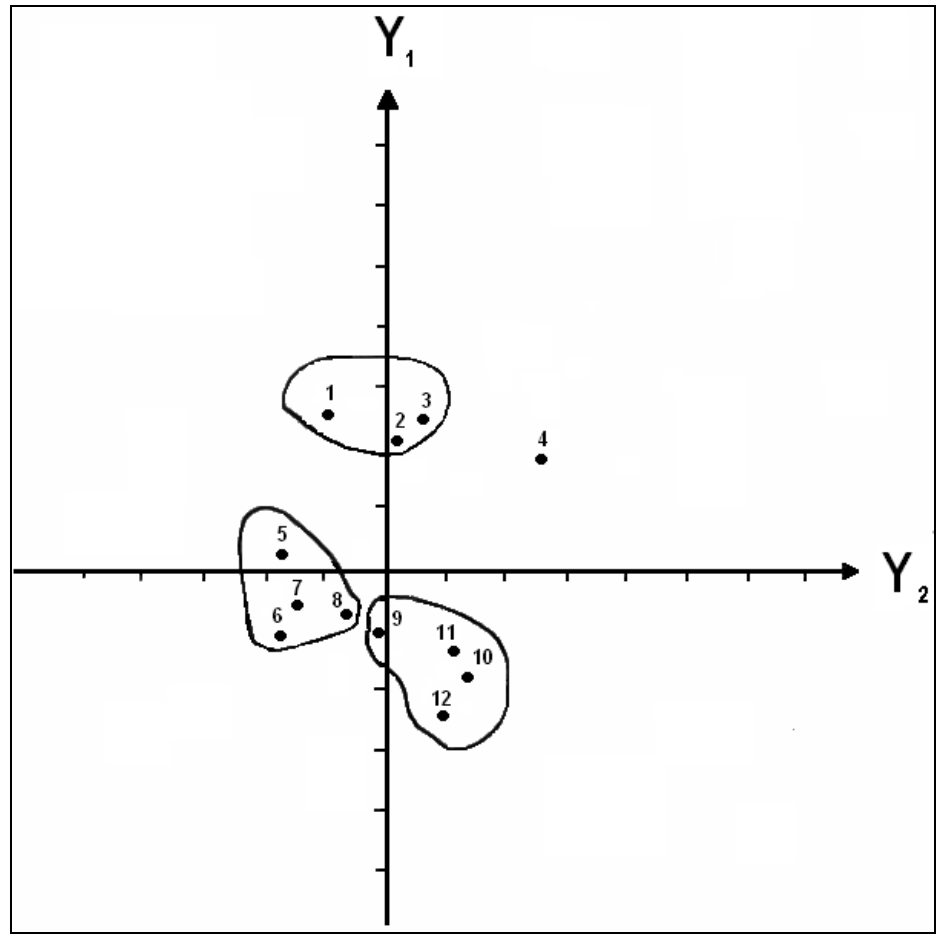

Figura 6. Ordenação das 12 amostras circulares estudadas, usando-se os dois primeiros componentes principais $\left(\mathrm{Y}_{1}\right.$ e $\left.\mathrm{Y}_{2}\right)$ com base em 7 variáveis do relevo.

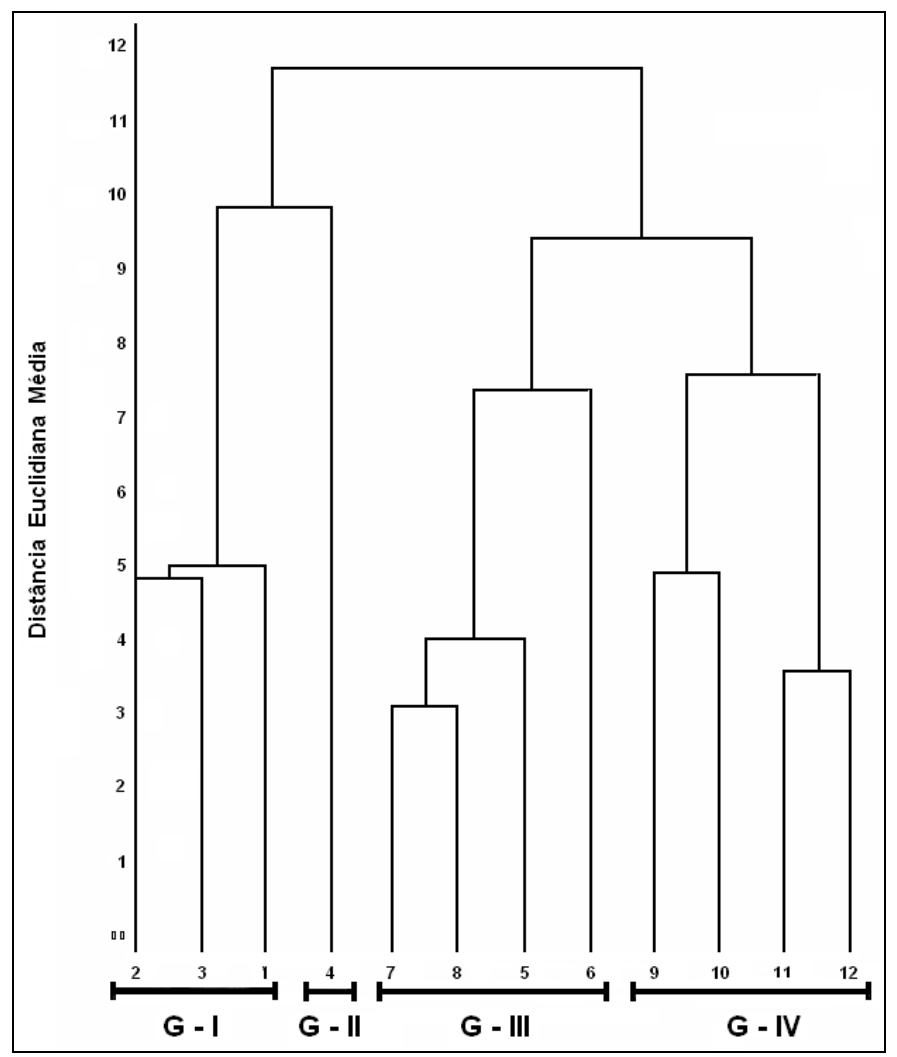

Figura 7. Fenograma ilustrativo da inter-relação das 12 amostras circulares estudadas e variáveis do relevo, utilizando-se como medida de semelhança a Distância Euclideana Média. 
As variáveis Hm, HM, Hmd e H que apresentaram significância ao nível de 5\% de probabilidade no teste " $\mathrm{t}$ " para todos os contrastes, foram as quatro variáveis que mais contribuíram por ordem de importância na formação dos agrupamentos G-I, G-II, G-III e G$\mathrm{IV}$, enquanto que as variáveis $\mathrm{Cd}, \mathrm{CVm}$ e I que foram não significativas no teste "t" para todos os contrastes, apresentaram-se também como as variáveis que menos contribuíram na formação dos agrupamentos, respectivamente, por ordem de importância na análise de agrupamento (BARROS et al., 2011).

Os resultados obtidos para as variáveis de relevo em função da localização de suas respectivas unidades de solo, através das amostras circulares permitiram constatar que a metodologia aplicada apresentou uma elevada concordância nos grupos formados (Figura 7), com exceção do Grupo II, formado pela amostra circular 4.

Assim, os índices do relevo HM, Hm, Hmd e I permitem inferir que foram eficientes na discriminação dos três solos.

\section{CONCLUSÕES}

Os resultados mostraram que as variáveis do relevo para amostras circulares mais eficientes na diferenciação dos solos foram HM, Hm, Hmd e $\mathrm{H}$ e quando submetidas à análise de agrupamento discriminaram $75 \%$ das amostras circulares representativas da unidade LVA e 100\% dos solos RL e RQ. A análise multivariada foi eficiente na discriminação dos solos RQ, LVA e RL quando foram utilizadas as variáveis do relevo para amostras circulares indicando a seguinte ordem de importância para estas variáveis: Hm, HM, Hmd, H, Cd, CVm e I, bem como foram mais eficientes na discriminação dos solos através da análise multivariada. As variáveis do relevo, submetidas à análise de agrupamento discriminaram $100 \%$ das bacias representativas das unidades LVA, RL e RQ.

\section{REFERÊNCIAS BIBLIOGRÁFICAS}

ANGULO FILHO, R. Características da rede de drenagem e do relevo de três solos do Estado de São Paulo através de fotografias aéreas e cartas planialtimétricas. Piracicaba: USP, 1986. 132p. Tese (Doutorado em Solos e Nutrição de Plantas). Escola Superior de Agricultura "Luiz de Queiróz", Universidade de São Paulo, 1986.

BARROS, Z.X. de. Caracterização de bacias hidrográficas no mapeamento de solos mediante o uso de análise multivariada. Botucatu: UNESP, 1988. 113p. Tese (Doutorado em Energia na Agricultura) - Faculdade de Ciências Agronômicas, Universidade Estadual Paulista, 1988.

BARROS, B.Z.X. de.; BARROS, Z.X. de; POLLO, R.A.; NASCIMENTO, F.M.; CAMPOS, S. Análise multivariada aplicada em bacias hidrográficas no Município de Botucatu. Irriga, Botucatu, v.16, n.3, p.351-359, 2011.

CAMPOS, S. Fotointerpretação da ocupação do solo e suas influências sobre a rede de drenagem da bacia do Rio Capivara - Botucatu (SP), no período de 1962 - 1977. 1993. 164f. Tese (Doutorado em Agronomia/Energia na Agricultura) - Faculdade de Ciências Agronômicas, Universidade Estadual Paulista, Botucatu, 1993. 
CAMPOS, S.; BARROS, Z.X. de. Comportamento da rede de drenagem na bacia do rio Capivara - Botucatu (SP), durante 15 anos. Energ. na Agríc., Botucatu, v.9, n.1, p.37-53, 1994.

CARDOSO, L.G. Comportamento das redes de drenagem em solos com cana-de-açúcar e com eucalipto. Botucatu: UNESP, 1988. 139 p. Tese (Doutorado em Energia na Agricultura) - Faculdade de Ciências Agronômicas, Universidade Estadual Paulista, 1988.

CRUZ, O. Alguns conhecimentos básicos por fotointerpretação. Aerofotogeometria. São Paulo, v.25, p.1-13, 1981.

CURI, P.R. A similaridade na análise de agrupamento: coeficientes de correlação e distância. Cienc. Cult. S. Paulo, n.11, p.1678-86. 1983.

HORTON, R.H.L. Erosional development of streams and their drainage basins hidrophysical approach to quantitative morphology. Bull.Geol.Soc.Am., Boulder, v.56, n.3, p.275330.1945 .

INSTITUTO BRASILEIRO DE GEOGRAFIA E ESTATÍSTICA. Cartas do Brasil. Superintendência de Cartografia do Ministério do Planejamento e Coordenação Geral do Brasil. Folha de Botucatu - SP, 1969.

KOFFLER, N.F. Análise do relevo a partir de índices de drenagem obtidos com fotografias aéreas. Bol.Geogr.Teorética. Rio Claro, v.12, n.23/24, p.69-76, 1982.

LIMA, S.L. Características da rede de drenagem e do relevo de três solos do Estado de São Paulo determinadas em fotografias aéreas e cartas planimétricas. Piracicaba: USP, 1987. 100p. Tese (Doutorado em Solos e Nutrição de Plantas) - Escola Superior de Agricultura "Luiz de Queiróz”- Universidade de São Paulo, 1987.

MOREIRA, L.; RODRIGUES, V.A. Análise morfométrica da microbacia da Fazenda Edgárdia - Botucatu (SP). .Eletr.Eng.Florestal. Garça, v.16, n.1, p.9-21, 2010.

SILVA, M.S. Fotointerpretação da rede de drenagem e do relevo de três solos do município de Botucatu - SP. Botucatu: UNESP, 1988. 163p. Tese (Doutorado em Energia na Agricultura) - Faculdade de Ciências Agronômicas, Universidade Estadual Paulista "Júlio de Mesquita Filho", 1988.

SILVA, C.M.; CATANEO, A.; CARDOSO, L.G. Sistema de planimetria digitalizada. In: JORNADA CIENTÍFICA DA ASSOCIAÇÃO DOS DOCENTES, Botucatu, 18, 1993. Anais... Botucatu - SP, JC, 1993,p.109.

SNEATH, P.H.A.; SOKAL, R.R. Numeral taxonomy. San Francisco, W.H. Freeman, 1973. $573 p$. 